\title{
Writing papers with an emphasis on structural geology and tectonics: advices and warnings
}

\author{
Haakon Fossen ${ }^{*}$ (iD
}

\begin{abstract}
The objective of this short paper was to provide some advice on how to write a geoscience paper of international standard and to warn against some common pitfalls. It is focused on how to structure a paper and stresses the importance of building its contents around a well-defined problem. Furthermore, the importance of moving away from outdated and counterproductive ways of describing and interpreting deformation is emphasized. In particular, describing structures and tectonic evolution in a poorly founded scheme of multiple deformation phases and making stress interpretations from structurally complex and heterogeneous rocks where rotations and stress perturbations are difficult or impossible to account for are strongly discouraged. Instead, I encourage the use of modern structural geology and tectonics ideas that, among other things, allow for composite and overprinting structures to form progressively and diachronously with a wide variation in style and orientation during a single deformation history. Also, more emphasis should be put on strain and kinematics, toning down the use of stress. After all, stress is only observed through strain and kinematics; going from one to the other is not straightforward in general, and particularly difficult in ductilely deformed rocks.
\end{abstract}

KEYWORDS: Scientific writing; Deformation phases; Progressive deformation; Stress; Strain.

\section{Introduction}

Writing a scientific geoscience paper that meets the standards of an international journal can be challenging, particularly when structural geology and tectonics are involved. It requires good knowledge of the scientific method, a solid and reproducible database to build the work on, deep insights into the relevant field(s) of science, a good overview of relevant published work and existing models, good communications skills, good language skills, critical and constructive advisors and reviewers, and a good portion of time and patience. This short paper provides some views and advices based on experience from the Brazilian Journal of Geology and papers from other journals dealing with Brazilian structural geology and tectonics.

This document is not a complete guide to writing an academic geoscience paper, but rather deals with specific issues that reappear in manuscripts submitted to BJG. Most of its contents also apply to Master and $\mathrm{PhD}$ theses, many of which form the basis for future international publications. General advice on academic paper writing can be found elsewhere (e.g., Mack 2018), and the editorial by Eriksson et al. (2005) is recommended as a guide for how to write and structure a geoscience paper. The present contribution has a generally applicable first part, and then focuses more specifically on structural

${ }^{1}$ Museum of Natural History/Department of Earth Science, University of Bergen - Bergen, Norway. E-mail: haakon.fossen@geo.uib.no

${ }^{*}$ Corresponding author.

(C) 2019 The autors. This is an open access article distributed under the terms of the Creative Commons license. geology and tectonics. It has been written to benefit future authors, particularly younger researchers with limited international publication experience but with ambitions to present Brazilian geology where it belongs: at a high international level.

\section{The structure of the paper}

The classic scientific paper follows the form Abstract, Introduction, Geologic setting, Method (particularly if geochronologic and experimental work is employed), Results, Discussion, and Conclusion, with a variety of appropriate subheadings. Method, Results and Discussion sections are sometimes given more creative and informative titles that relate more directly to their contents, and other deviations from this structure certainly occur (particularly for review papers and certainly for the current contribution). Nevertheless, this is the structure that fits the majority of geoscience papers.

Some papers are based on Master theses. In this case, make sure that the text does not read like a condensed version of the thesis. A thesis contains methodological and other information that is not needed in an international paper, such as number of field seasons, type of compass used, and number of measurements (these are better exposed as " $n=$ ??" in figures and graphs). Similarly, excessive descriptions of rocks and their mineral constituents and lengthy introductions to the geology of the region should generally be avoided. A scientific paper should be problem oriented, and descriptive only for the purpose of providing a basis for defining and solving the problem in question, as emphasized below. 


\section{Defining a problem and a hypothesis to be tested (the Introduction)}

An important objective for many journals published by national geological surveys, universities and local (e.g., state) geology associations is to publish data, maps and descriptions of the geology of the related geographic region. The purpose of the BJG and other international journals is different. For a paper to be of interest to the BJG, an academic problem or question needs to be presented. This should be presented right from the start, primarily in the introduction but also very briefly and concisely in the beginning of the abstract. If the authors think they have a good hypothesis related to the question, that too should be presented in the Introduction, and then tested scientifically later in the paper. Basically, the purpose of the paper must be crystal clear from the beginning, and should be to solve a question of general (international) interest, based on logical reasoning and scientifically sound data relevant to the problem in question. In this context, various types of data, including local maps and field observations, can be introduced, but only if they are needed for discussing the main question/hypothesis.

As an example taken from a recent BJG paper, Peixoto et al. (2018) define the purpose of their paper very well:

"Deciphering the internal architecture of the Rio Pardo salient and understanding its kinematic history is, however, crucial for testing the models postulated for the development of the AWCO as a confined orogenic system. ... How did the Rio Pardo salient originate? Was its generation governed by attributes of the Macaúbas basin? If so, which pre-orogenic features controlled its development? Was the salient generation coupled with any rotation component? How was the WSW-ENE shortening documented in the intracratonic Paramirim aulacogen accommodated inside the salient? In order to provide answers to these key questions and to contribute to the understanding of the evolution of the Rio Pardo salient and to f-tbelt curves in general, we carried out a field-based structural investigation in the northern Araçuaí orogen, involving the description of c. 700 outcrop stations along a $160 \mathrm{~km}$-wide and $340 \mathrm{~km}$-long area (Fig. 1).”

Importantly, they also put the origin and implications of such salients into a global context, highlighting the international or global significance of their work. If you have a manuscript or dataset of local character, try to find an aspect of your work that may be of general interest, and focus on that. Often times this means excluding some irrelevant data and perhaps obtaining some additional data. In other cases, the work is better presented in a more local or survey journal.

At the end of the introduction, it may be useful to reveal both the flow of the paper and indicate the main conclusions. Peixoto et al. (2018) do this in the following way:

"After addressing the geological context and previous investigations on the Rio Pardo salient, we provide a description of its overall architecture, deformation phases and related fabric elements, which is then followed by a discussion on the implications of our data and our interpretations. We conclude by postulating a model for the generation of the Rio Pardo salient in the tectonic scenario of the development of the AraçuaíWest Congo orogenic system.”

The statement would be even better by briefly mentioning the new model already at this point, instead of disclosing it until the end (we are not writing a crime novel). Note that there is no separate methodology section in Peixoto et al. (2018), because their work was based on well-established structural and kinematic field methodology that require no detailed description.

\section{Statements should be supported by data or logical arguments}

Too often do we see manuscripts with statements that are not explained or supported by data. Scientifically isolated statements are of no value to the reader, who will always want to know the basis for the statement. Consider the statement "Unit A was thrusted to the west, over unit B". The following is a better statement: "A mylonite zone at the base of Unit A exhibits kinematic structures consistent with westward thrusting over Unit B”.

Statements should not only be backed up by facts, but also need to be presented in a logical order, where one statement leads to the next. The text needs to flow. This also means that every statement should be there for a reason, as part of a larger intellectual construction that relates to the initially defined purpose of the paper.

\section{The English language}

While writing a good scientific text in your mother tongue is already challenging, writing in a second language can be rightout frustrating. Nevertheless, a submitted text must be written in a clear way, and poor language skills must never compromise its scientific contents and general readability. It is necessary to have a person with very good knowledge of English scientific writing go through the text. If there is a need for substantial corrections, it would be beneficial if that person has some knowledge of the author's mother tongue (usually Portuguese in the case of BJG) to better interpret and fix awkward wording and non-English sentence constructions and at the same time maintain the intended meaning.

\section{Deformation phases}

Reading papers on Brazilian geology, including the paper mentioned above (Peixoto et al. 2018), one can easily get the impression that there are more phases of deformation in Brazil than elsewhere. This is of course not the case, but relates to the excessive and old-fashioned use of the concept of deformation phases in Brazil. Deformation phases certainly exist, and in some cases it is both possible and useful to distinguish between different phases of deformation based on a combination of several independent criteria, such as structural overprinting, stratigraphic evidence, metamorphic and microtextural characteristics, P-T estimates, and geochronologic evidence. 
Deformation phases can only be correctly identified through careful investigation and combination of different types of evidence, followed by a discussion that also considers alternative interpretations. It is therefore a fundamental scientific problem that many manuscripts submitted to the BJG start out with a pre-defined scheme of deformation phases $\left(\mathrm{D}_{1}, \mathrm{D}_{2}, \ldots\right)$, often times as many as 5 or 6 . Typically, there is no explanation as to how the scheme was constructed, although it appears in most cases that it was based on structural style and overprinting relations observed in individual outcrops that were then correlated and generalized for a larger region. However, even if two foliations or a refolding pattern can be distinguished within a field area, this is not proof of two deformation phases. They could both have formed during one single phase of deformation, unless independent data suggest otherwise.

The concept of deformation phases was widely applied in the 1960s and 70s, even though it was warned that deformation is often diachronous (Chadwick 1968) and that correlating outcrops in terms of structural style and overprinting is inherently difficult since significant spatial variations occur as a function of lithology (rheology) and strain (e.g., Park 1969, Williams 1970). In other words, different lithologies develop structures differently, and structures also rotate and evolve as strain increases. Uncritical use of the concept of deformation phases was still to be found in international journals in the 1980s. Tobisch and Paterson (1988) captured the problem well, stating that:

"The use of chronological subscripts for structural elements in complexly deformed regions was originally conceived on the assumption that all structures of like morphology and orientation have formed contemporaneously. We now know that this assumption is highly questionable, especially in ductile shear zones, but we continue to use chronological notation even though it can set the stage for unrealistic interpretations of how the rock body deforms."

Next, we will discuss some key factors that complicate the use of the concept of deformation phases, and that should be taken into consideration during structural analysis in general.

\section{Complications caused by strain variations}

Homogeneous strain over large areas is unusual, hence we should not be surprised to find a variation in structural style across our study area, where a given planar fabric could vary from almost absent to becoming the dominant foliation. This would go along with a change in foliation character, say from a faint crenulation cleavage to a penetrative slaty cleavage or schistosity, and also with a change in orientation. Similarly, folds could be expected to change in style from open to tight, perhaps together with a change in orientation from upright to recumbent. When dealing with observations from a limited number of outcrops in a poorly exposed area (a common situation in Brazil), structural correlation between outcrops may be challenging. And when the tectonic flow and resulting strain field become three-dimensional, things get even more complicated. Using transpression as an example, a situation may occur where the lineation changes from horizontal to vertical as strain accumulates during a single steady-state deformation (Tikoff \& Green 1997).

\section{Complications caused by strain partitioning}

Once we consider strain partitioning, where different types of strain (for example pure shear and simple shear) are distributed unevenly across a region, further complications arise. In these cases, there may be, for instance, zones of simple shear separating zones of more coaxial deformation. Structures forming at different locations during the same phase of deformation could then be very different in different parts of the region (see Holdsworth et al. 2002, for an example).

\section{Complications during progressive deformation}

If we go on and consider all the local complications that can occur during a single phase of non-coaxial deformation, the concept of deformation phases gets quite complicated to deal with. For instance, perfect simple shear as portrayed by Ramsay (1980) is a very nice reference model, but reality is usually more complicated. In perfect simple shear, the foliation is a plane of flattening that rotates toward the shear plane, but never reaches it. Therefore, folded boudins should be impossible in simple shear, and was in the older literature considered as evidence for a later phase of deformation. In reality, progressive shearing involves many complications, such as the rotation of the foliation through the shear plane due to flow perturbations. The result may be not only folded boudins, but also flanking structures and sheath folds - folds with hinges that at low strain stages made a high angle to the lineation, but end up more or less parallel to this direction (e.g., Brun \& Choukroune 1981, Cobbold \& Quinquis 1980). Furthermore, local folding, refolding and cleavage formation can occur at any time during progressive shearing (Holdsworth 1990). These local structures and their overprinting relations cannot be correlated regionally, between outcrops or even within outcrops in many cases, and hence have no meaning in terms of deformation phases.

\section{Complications caused by non-steady state deformation}

The concept of deformation phases implies that deformation was steady state (constant flow) during each phase. This means that the regional or local stress or kinematic boundary conditions remained fixed throughout the deformation phase. This is an idealized assumption, and non-steady state deformation is probably quite common. This means that the way structures form and evolve over the course of deformation can be highly unpredictable.

\section{Additional complications caused by soft-sediment deformation}

Another pitfall when dealing with deformation phases in metasedimentary rocks relates to soft-sediment deformation structures, i.e. structures forming in sediments prior to lithification and often very soon after deposition. Soft-sediment deformations (see Obermeier 1996, Montenat et al.2007) are typically related to syn-sedimentary seismic activity, fluid overpressure and/or dewatering of sediments. Such deformation can produce folds and faults with a range in style, and tight or 
even isoclinal folds with inverted flanks are not uncommon. This type of primary deformation is typically confined to layers between undeformed layers. Even refolding patterns may result from soft-sediment deformation. The addition of a single regional deformation phase can then produce a complex structural pattern that can easily be misinterpreted as the result of polyphase tectonic deformation. Such a misinterpretation will confuse any attempt to understand the true tectonic history of the region.

\section{Concluding point regarding deformation phases and related nomenclature}

Increasing awareness of the above-mentioned factors has ended the often uncritical and excessive use of deformation phases of the 1960s and 70s in most international journals. At that time, it appeared that the more deformation phases you could define, the better your structural analysis. The opposite should be the case, because in science there is a basic principle that tells us to look for the simplest model that can explain our observations. Thus, if deformation phases are to be defined, a line of scientific arguments needs to be built for each of them, and they should be connected to large-scale tectonic events. Geochronologic data that clearly demonstrate a time difference between different structural associations is usually the preferred type of data in this context (e.g., Oriolo et al. 2018).

It can be conclude that the use of chronologic nomenclature of the type $\mathrm{D}_{1}, \mathrm{D}_{2}, \ldots$ should be avoided in most cases, and in particular in the descriptive first part of a paper. Instead, structures should be described in a way that opens for discussions about the deformation history in the last part of the paper. Structural descriptions should be done as objectively as possible, and in the context of strain, kinematics, stratigraphy and rheology/lithology. It may be desirable to name different kinds of foliations and folds, but these should be treated in terms of morphology rather than deformation phases, as emphasized by Tobisch and Paterson (1988). For example, the names $S_{t}$ for transposition foliation, $S_{c}$ for crenulation cleavage, $S_{s c}$ for slaty cleavage, and $S_{m}$ for mylonitic foliation could be used. Then their chronologic relations could be dealt with in the Discussion section, together with independent geochronologic data and regional tectonic information. For further discussion of the concept of deformation phases in the context of modern structural geology, see Fossen et al. (2019).

\section{Use and abuse of the term stress}

Another major point of concern regards the excessive and often inappropriate use of the terms stress and principal stress directions $\left(\sigma_{1}, \sigma_{2}\right.$, and $\left.\sigma_{3}\right)$. Stress in naturally deformed rocks is inherently difficult to deal with, because stress can never be directly observed. Information about stress is always derived from strain and kinematic analysis. Furthermore, only structures involving very small strains should ideally be used to constrain stress orientations. Paleostress at the scale of an outcrop can be constrained by the kinematics and orientations of brittle structures (shear fractures, extension fractures, veins, dikes and stylolites) (e.g., Angelier 1979) and by calcite deformation twins (e.g., Craddock \& van der Pluijm 1999, Lacombe 2010). However, even for brittle deformation, the complications caused by block rotations, reorientation of the stress field around weak or strong structures, progressive rotation of local stress due to fracture growth and interaction (Gapais et al.2000, Riller et al. 2017, Simón 2019) has led many geologists to refer to strain and strain rate axes (instantaneous stretching axes) rather than stress axes (Twiss \& Unruh 1998). For example, it is better to use extension direction (a strain term) than stress directions when discussing rifting. Note that the above listed complications can also lead to an overestimate of brittle deformation phases, as pointed out by Riller et al. (2017). Hence much of the above discussion of use and abuse of deformation phases also applies to the brittle field.

While paleostress analysis may sometimes be possible for brittle structures, complications increase dramatically in the ductile regime, where the effect of anisotropy, rotations and geometric complications on the structural development is more significant and less predictable. In general, stress orientations cannot be inferred from structural analysis of complexly deformed rocks in the ductile regime, even though this appears to be taught almost routinely at most Brazilian universities. Structural analyses in this regime must be made in terms of finite and, if possible, incremental strain, vorticity and kinematics. If in doubt, use strain instead of stress terminology, and always when dealing with ductilely deformed rocks. For more discussion of paleostress in rocks, see Marrett \& Peacock (1999) and Tikoff \& Wojtal (1999). And in terms of nomenclature, reserve the terms tension and compression for stress and apply terms like contraction, shortening, extension, and stretching when referring to strain and structures.

\section{What to focus on}

One may wonder what to focus on if the common counting of deformation phases and stress interpretations are to be toned down or omitted. An important part of the answer is to break loose from the traditional descriptive structural geology and tectonic models that have been inherited and repeated in the geoscience community in Brazil for quite some time. For any science to advance it is necessary to think new and test out alternative models. Hence, we all should appreciate and encourage such attempts. A prerequisite for making progress in structural geology and tectonics is, naturally, to thoroughly understand modern theory and methods, with their possibilities and limitations. Counting deformation phases is easy and requires little insight into modern structural geology, and it adds little or negatively to the advance of geologic knowledge. This does not mean that field-based structural analysis and fabric descriptions are outdated, far from it. It just means that field-based observations must be unleashed from predefined schemes to become more objective, and then analyzed and interpreted in the context of modern structural geology and tectonics. Furthermore, integrating finite strain, fabric development, kinematics, vorticity analysis, and incremental strain data, and combining this type of structural data with geochronologic information, geophysical data and perhaps also physical 
or numerical modeling is recommended. In particular, strategic dating of minerals, dikes or other elements that can constrain the structural evolution in time is invaluable.

Understanding the rheologic implications of rocks and fabrics and their relation to tectonic evolution can also be rewarding. For example, being able to differentiate between magmatic and solid-state deformation in rocks is crucial for understanding the nature of hot crustal flow. Rheology and preexisting structures are linked to partitioning of deformation, which appear to be both common and important in many tectonic settings and at different scales. This also relates to deformation phases. For instance, the occurrence of thrusting and strike-slip deformation in a region does not necessarily imply two phases of deformation: the possibility that they developed during the same regional strain field should be considered equally likely until solid evidence for one of the two interpretations is found. Hence, the effect of deformation partitioning and heterogeneous deformation should be on the mind of anyone involved in structural analysis.

Further, methodology now exists that takes structural geology down to the microscale in a new way. The Electron Backscatter Diffraction (EBSD) is such a technique, now available in some Brazilian universities. This tool should be carefully combined with other structural analysis to explore crustal deformation at macroscale. Also, combining such information with various pressure-temperature data is useful. Magnetic fabrics (Anisotropy of Magnetic Susceptibility) is yet another method that can reveal fabric patterns in rocks, such as magmatic-state as well as solid-state deformation that would otherwise be difficult to extract by classical field methods.

Finally, I also recommend employing digital mapping tools that allow for more efficient data collection and analysis. Currently, the most useful free field apps for basic mapping and sampling are Midland Valley's Fieldmove Clino and Fieldmove (mve.com/digital-mapping). Other useful iOS apps, particularly Stereonet Mobile, FaultKin for iOS, and GMDE Mobile iPad App, are provided by Rich Allmendinger (Allmendinger et al. 2017) (geo.cornell.edu/geology/faculty/RWA/programs/).

\section{Summary}

1. Any paper must be built around a question or hypothesis of general interest to the readership;

2. This question must be clearly defined in the introduction, together with information about how it will be approached. Furthermore, it must be returned to in the discussion/ conclusion, where the achievement made towards answering the question should be clearly portrayed;

3. The text must flow in a logical way, where statements are backed by appropriate scientific references, descriptions and data. Even in the Abstract, statements should be coupled with methodology and results;

4. Even though it may seem convenient; never put structural descriptions into a pre-defined scheme of deformation phases. Deformation phases are something that can be brought up in the Discussion, based on observations and data objectively presented in the main part of the paper;

5. The exercise of defining a large number of deformation phases based on overprinting relations alone should be avoided;

6. Do not overuse the term stress. When using stress, there is a good chance that you actually mean strain;

7. Never make inferences about stress orientations based on ductile (plastic) deformation structures. Instead, relate structures to strain (finite or incremental) and kinematics;

8. Make sure that the content is not cluttered by poor English, which for most of us means getting help from colleagues and professional proofreaders;

9. If you are uncertain if your manuscript fits into a specific journal, it may be a good idea to email the Editor for advice prior to submission.

\section{ACKNOWLEDGMENTS}

Thanks to Carolina Cavalcante and Chief Editor Claudio Riccomini for reading through the text and making suggestions of improvements, and to Carlos Archanjo for reviewing the text.

\section{ARTICLE INFORMATION}

Manuscript ID: 20190109. Received on: 10/14/2019. Accepted on: 11/04/2019.

H. F. wrote the manuscript and incorporated some suggestions provided by Carolina Cavalcante, the reviewer and the Editor in Chief. Competing interests: The author declare no competing interests.

\section{REFERENCES}

Allmendinger R.W., Siron C.R., Scott C.P. 2017. Structural data collection with mobile devices: Accuracy, redundancy, and best practices. Journal of Structural Geology, 102:98-112. http://doi.org/10.1016/j.jsg.2017.07.011

Angelier J. 1979. Determination of the mean principal directions of stresses for a given fault population. Tectonophysics, 56(3-4):T17-T26. https://doi. org/10.1016/0040-1951(79)90081-7

Brun J.P., Choukroune P. 1981. Déformation progressive et structures crustales. Revue de Géologie Dynamique et de Géographie Physique, 23(3):117-193

ChadwickB. 1968.Deformation and metamorphismin the Lukmanier region, central Switzerland. Geological Society of America Bulletin, 79(9):1123-1150. https://doi.org/10.1130/0016-7606(1968)79[1123:DAMITL]2.0.CO;2
Cobbold P.R., Quinquis H. 1980. Development of sheath folds in shear regions. Journal of Structural Geology, 2(1-2):119-126. https://doi. org/10.1016/0191-8141(80)90041-3

Craddock J.P. \& van der Pluijm, B. 1999. Sevier-Laramide deformation of the continental interior from calcite twinning analysis, west-central North America. Tectonophysics, 305(1):275-286. https://doi.org/10.1016/ S0040-1951(99)00008-6

Eriksson P., Altermann W., Catuneanu O. 2005. Some general advice for writing a scientific paper. Journal of African Earth Sciences, 41:285-288. https://doi.org/10.1016/j.jafrearsci.2005.06.001

Fossen H., Cavalcante G.C.G., Pinheiro R.V.L., Archanjo C.J. 2019 Deformation - Progressive or multiphase? Journal of Structural Geology, 125:82-99. http://dx.doi.org/10.1016/j.jsg.2018.05.006 
Gapais D., Cobbold P.R., Borgeois O., Rouby D., Urreiztieta M.D. 2000. Tectonic significance of fault-slip data. Journal of Structural Geology, 22(7):881-888. https://doi.org/10.1016/S0191-8141(00)00015-8

Holdsworth R.E. 1990. Progressive deformation structures associated with ductile thrusts in the Moine Nappe, Sutherland, N. Scotland. Journal of Structural Geology, 12(4):443-452. https://doi. org/10.1016/0191-8141(90)90033-U

Holdsworth R.E., Tavarnelli E., Clegg P., Pinheiro R.V.L., Jones R.R., McCaffrey K.J.W. 2002. Domainal deformation patterns and strain partitioning during transpression: an example from the Southern Uplands terrane, Scotland. Journal of the Geological Society, 159:401-415. https://doi. org/10.1144/0016-764901-123

Lacombe O. 2010. Calcite Twins, a Tool for Tectonic Studies in Thrust Belts and Stable Orogenic Forelands. Oil \& Gas Science and Technology, 65(6):809-838. https://doi.org/10.2516/ogst/2009088

Mack C.A. 2018. How to write a good scientific paper. Washington, Society of Photo-Optical Instrumentation Engineers (SPIE), 108 p.

Marrett R. \& Peacock D.C.P. 1999. Strain and stress: Journal of Structural Geology, 21(8-9):1057-1063. https://doi.org/10.1016/ S0191-8141(99)00020-6

Montenat C., Barrier P., Ott d'Estevou P., Hibsch C. 2007. Seismites: An attempt at critical analysis and classification. Sedimentary Geology, 196(1):530. http://dx.doi.org/10.1016/j.sedgeo.2006.08.004

Obermeier S.F. 1996. Use of liquefaction-induced features for paleoseismic analysis - an overview of how seismic liquefaction features can be distinguished from other features and how their regional distribution and properties of source sediment can be used to infer the location and strength of Holocene paleo-earthquakes. Engineering Geology, 44(1-4):1-76.

Oriolo S., Wemmer K., Oyhantçabal P., Fossen H., Schulz B., Siegesmund S. 2018. Geochronology of shear zones - A review. Earth-Science Reviews, 185:665-683. https://doi.org/10.1016/j.earscirev.2018.07.007
Park R.G. 1969. Structural correlation in metamorphic belts. Tectonophysics, 7(4):323-338. https://doi.org/10.1016/0040-1951(69)90077-8

Peixoto E., Alkmim F.F., Pedrosa-Soares A.C. 2018. The Rio Pardo salient, northern Araçuaí orogen: an example of a complex basin-controlled foldthrust belt curve. Brazilian Journal of Geology, 48(1):25-49. http://dx.doi. org/10.1590/2317-4889201820170134

Ramsay J.G. 1980. Shear zone geometry: a review. Journal of Structural Geology, 2(1-2):83-99. https://doi.org/10.1016/0191-8141(80)90038-3

Riller U., Clark M.D., Daxberger H., Doman D., Lenauer I., Plath S., Santimano T.2017. Fault-slip inversions: Their importance in terms of strain, heterogeneity, and kinematics of brittle deformation. Journal of Structural Geology, 101:80-95. http://dx.doi.org/10.1016/j.jsg.2017.06.013

Simón J.L. 2019. Forty years of paleostress analysis: has it attained maturity? Journal of Structural Geology, 125:124-133. http://dx.doi.org/10.1016/j.jsg.2018.02.011

Tikoff B., Greene D. 1997. Stretching lineations in transpressional shear zones: an example from the Sierra Nevada Batholith, California. Journal of Structural Geology, 19(1):29-39. https://doi.org/10.1016/ S0191-8141(96)00056-9

Tikoff B., Wojtal S.F. 1999. Displacement control of geologic structures. Journal of Structural Geology, 21(8-9):959-967. https://doi.org/10.1016/ S0191-8141(99)00045-0

Tobisch O.T., Paterson S.R. 1988. Analysis and interpretation of composite foliations in areas of progressive deformation. Journal of Structural Geology, 10(7):745-754. https://doi.org/10.1016/0191-8141(88)90081-8

Twiss R.J., Unruh J.R. 1998. Analysis of fault slip inversions: do they constrain stress or strain rate? Journal of Geophysical Research, 103(B6):12,205-12,222.

Williams P.F. 1970. A criticism of the use of style in the study of deformed rocks. Geological Society of America Bulletin, 81 (11):3283-3296. https://doi. org/10.1130/0016-7606(1970)81[3283:ACOTUO]2.0.CO;2 